Corresponding Author:

Mohammad Azizi

Department of Exercise

Physiology, Faculty of Sport

Sciences, Razi University,

Kermanshah, Iran

email:

azizimihammad@gmail.com

Production and Hosting by

Knowledge E

(c) Maryam Lotfi et al. This article is distributed under the terms of the Creative

Commons Attribution License,

which permits unrestricted use and redistribution provided that the original author and source are credited.

Editor-in-Chief: Dr. Alireza Rafiei

\section{Acute Beetroot Juice Intake: Hematological, Antioxidant and Lipid Parameters in Female Athletes}

\section{Maryam Lotfi ${ }^{1}$, Mohammad Azizi ${ }^{1}$, Worya Tahmasebi ${ }^{1}$, and Parviz Bashiri ${ }^{2}$}

${ }^{1}$ Department of Exercise Physiology, Faculty of Sport Sciences, Razi University, Kermanshah, Iran ${ }^{2}$ Department of Animal Science, Faculty of Agriculture and Natural Resources, Razi University, Kermanshah, Iran

\section{Abstract}

Background: One of the drinks that are increasingly popular among athletes is beetroot juice. This survey was undertaken to determine the effects of acute beetroot juice consumption on certain hematological parameters, lipid profiles, and total antioxidant capacity in female soccer players.

Materials and Methods: This was an applied, semi-experimental study. Female soccer players $(n=30$, age $=23.16 \pm 0.79$ years) were selected randomly and assigned into three groups: experimental (beetroot juice, $n=10$ ), (control (placebo), $n=10$ ) and (mouth rinsing, $n=10$ ). Subjects undertook soccer training for a session (90 min) with consumption of $200 \mathrm{ml}$ juice $2 \mathrm{~h}$ before they started. Blood samples were collected and investigated before and after training. Paired sample t-tests were used for comparison within groups, and one-way ANOVA was used for comparison between groups. All statistical analyses were performed at $P \leq 0.05$.

Results: After a session of using beetroot juice, there were no significant differences in blood indices (levels of hemoglobin, hematocrit, red blood cells, iron, and mean corpuscular volume), lipid profiles (triglycerides, total cholesterol, and high density lipoprotein), and total antioxidant capacity between groups (experimental, control, and mouth rinsing) $(P>0.05)$, but low density lipoprotein concentrations changed significantly $(P<0.0001)$.

Conclusions: Drinking a dose of beetroot juice did not improve hematological parameters, lipid profiles, and total antioxidant capacity. Therefore, our study of daily consumption of this drink will be pointed out to subsequent researchers.

Keywords: Beetroot juice, Female Soccer players, Training

Anemia is defined as a decline in one or more of the major RBC (Red Blood Cell) measurements: hemoglobin concentration, hematocrit, or red blood cell count. It is a disorder caused by nutritional deficiency involving iron, minerals, folic acid and vitamins [1]. The element iron is especially important for oxygen transport during exercise. Lack of iron makes the body unable to produce red blood cells and deliver sufficient oxygen to 
muscle, brain and other organs [2-4]. Athletes, especially female soccer players, are more sensitive to the effects of iron deficiency anemia because exercise depends on the maximum oxygen carrying capacity to active muscles and the beneficial use of oxygen by such muscles. Anemia due to iron deficiency can also reduce exercise performance [5]. Measurement of hemoglobin concentration is one means of checking anemia in female soccer players. Also regular monitoring of iron stores and red blood cell parameters are necessary to prescribe nutritional supplements if signs of anemia observed. Among vegetables, beetroot is an extraordinary source of nutrients, including potassium, beta-alanine, sodium, iron, folic acid, magnesium, and nitrate. The benefits of using beetroot juice in human cases (non-athletes) are treating anemia by increasing red blood cell count, improving blood circulation, enhancing oxygen carrying capacity of erythrocytes (RBCs) and improving menstrual problems [6]. Until now, the effects of acute beetroot juice intake on blood indices in athletes has not been investigated. Moreover, as we know, hypercholesterolemia and hyperlipidemia are risk factors for the prevalence of hypertension, atherosclerosis and cardiovascular diseases [7]. Several studies have shown that there is a direct relationship between high blood pressure and elevated levels of (TC (Total Cholesterol), TG (Triglyceride) and LDL (Low Density Lipoprotein)). Evidence has shown that beetroot juice consumption has beneficial physiological effects and may treat several diseases such as high blood pressure and atherosclerosis [8]. Research has attributed the effects of lowering blood pressure by beetroot juice to inorganic nitrate [9]. Until now, no research has been conducted regarding the effects of beetroot juice consumption on lipid profiles in female soccer players. On the contrary, extensive peroxidation of lipids changes the assembly, composition and structure of lipid membranes. In fact, lipid peroxides are key mediators of many disorders such as inflammation and cancer [10]. Lipid peroxides are able to develop further production of ROS (Reactive Oxygen Species), which can alter cellular components. Furthermore, energy production in sports such as soccer depends on both aerobic and anaerobic pathways, which generate free radicals as a consequence. Oxidative stress is a condition that free radicals levels increases from the capacity of endogenous antioxidant defense systems. There are number of key factors that affect oxidative stress: the type, intensity, frequency and duration of the training. Although intensive physical activity is known to increase oxidative stress, studies have demonstrated that regular exercise increases indices of antioxidant defense [11]. Presently, athletes use antioxidant supplementation to enhance their antioxidant capacity [12]. Beetroot juice is one of the drinks that is increasingly popular among athletes. Beetroot contains pigments called betalains that are composed 
of vulgaxanthin I, vulgaxanthin II, indicaxanthin, betanin, prebetanin, isobetanin, neobetanin and a pool of phenolic compounds that includes phenolic acids, flavonoids, organic and inorganic acids [13]. Beetroot also includes smaller amounts of other compounds, such as ascorbic acid, which may further increase the total antioxidant capacity and enhance the body's ability to fight with reactive oxygen species [14]. Researchers have probed the effects of acute and chronic consumption of beetroot juice in individuals and athletes [15-17]. There is still a lack of evidence, which prevents any recommendations for clinical use of beetroot juice in female soccer players. Objective: The purpose of this study was to investigate the effects of acute beetroot juice consumption on certain hematological parameters, lipid profiles and total antioxidant capacity in female soccer players. In summary, we sought to investigate potential advantages of acute beetroot juice consumption in female soccer players.

\section{Materials and Methods}

\subsection{Study design}

This study was approved by the Science Ethics Committee of Medical Sciences, Razi University, Kermanshah, Iran (Ethical code: IR.KUMS.REC.1397.655). This was an applied, semi-experimental study. Inclusion criteria for the study encompassed:

- Participants must be trained soccer players (having 3-4 year training history in soccer)

- They must not be addicted to or use alcoholic drinks

- Not having history of certain diseases such as cancer, kidney stones, cardiovascular disease.

Exclusion criteria to the study included: vomiting, diarrhea, and beetroot allergy during the study. After explaining the aims and procedures of the study, written consent was provided by subjects. The research population consisted of young trained female soccer players ( $n=30$, age: $23.16 \pm 0.79$ ) who played in the Razi University soccer team. They took part in the study voluntarily, so we had limits on the number of subjects. Each subject's health status was assessed by a questionnaire. Anthropometric characteristics of subjects were measured in the first session (Table 1). Then, subjects were categorized randomly into three groups (experimental, control, and mouth rinsing) $(n=10)$. This research lasted for one session (90 minutes). 


\subsubsection{Anthropometric measurements}

Height was measured by a height measurement device (seca model) and weight measurement was done by a Digital scale with $100 \mathrm{~g}$ sensitivity. BMI measurement was done by a body composition analyzer device (inbody 270 ) in the first session. Anthropometry assessments (Height, weight, BMI) are shown in the (Table 1).

\subsubsection{Nutritional intervention}

Subjects lived in the dormitory of Razi University and consumed food provided by a central canteen. Before the implementation of the research protocol, we monitored and controlled their diet. A list of nitrate-containing vegetables (celery, tomato, watermelon, lettuce, cabbage) were given to subjects, who were instructed not to use them during the study. Subjects were asked not to use supplementations and energy beverages throughout the study. The food provided by the central canteen did not contain nitrate and was controlled. Subjects ingested $200 \mathrm{ml}$ concentrated beetroot juice, placebo (red carmoisine food color and a small dose of stevia (a sweetener) dissolved in the water) and beetroot juice was used for mouth rinsing (in this method, subjects swirled $200 \mathrm{ml}$ of concentrated beetroot juice in their mouth) $2 \mathrm{~h}$ before subjects started sports training [18].

\subsubsection{Biochemical parameter measurements}

Prior to implementing the research protocol, we consulted with a laboratory specialist for blood sampling. Due to the large number of parameters, we decided to take $10 \mathrm{ml}$ blood samples from each subject. Blood samples were collected by a laboratory specialist 24 $\mathrm{h}$ before and after trials, and hematological parameters (hemoglobin, hematocrit, RBC, iron and MCV) and lipid profiles (triglycerides, total cholesterol, high density lipoprotein and low density lipoprotein) were measured in the pre-test and post-test. Then, data were compared for the pre-test and post-test results (Tables 2, 3). 


\subsubsection{TAC $^{6}$ measurement}

Blood serum was separated from plasma and tested with Zellbio total antioxidant capacity (TAC) kits. Optical Density (OD) was measured using an ELISA plate reader. We calculated differences by the formula below. Then, the pre-test and post-test total antioxidant capacities were compared (Tables 2, 3).

$$
O D=O D_{2}-O D_{1}
$$

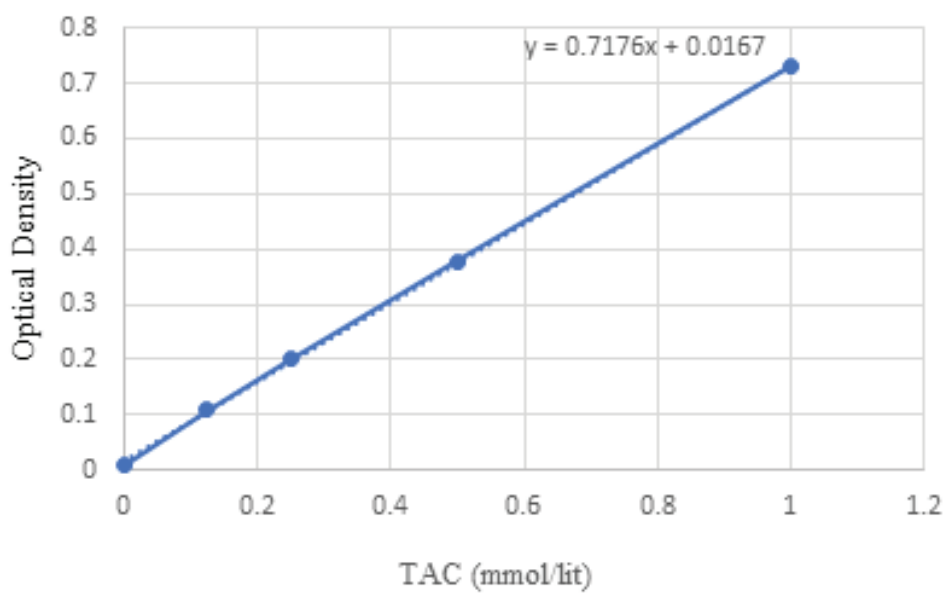

Figure 1: Total Antioxidant Capacity (TAC) (mmol/l)

\subsubsection{Statistics}

Data were analyzed using SPSS software (version 22) and expressed as mean \pm standard deviation (SD). According to Kolmogorov-Smirnov testing, the data were normally distributed. Comparison within groups was done by paired sample t-test, and comparison between groups was conducted by one-way ANOVA. Statistical significance was considered at $\mathrm{P} \leq 0.05$.

\section{Results}

\subsection{Physiological characteristics}

After drinking beetroot juice followed by soccer training, changes identified in the concentration of hematological parameters were not meaningful. This means that there were no significant differences between the pre-test and post-test scores of the blood indices in the experimental group $(\mathrm{Hb}: \mathrm{P}=0.39, \mathrm{HCT}: \mathrm{P}=0.17$, RBC: $\mathrm{P}=0.52$, Iron: $\mathrm{P}=$ 
TABLE 1: Anthropometric measurements (Weight, Height, BMI) (Mean \pm SD).

Variable
Age (years)
Weight $(\mathrm{kg})$
Height $(\mathrm{cm})$
BMI $\left(\mathrm{kg} / \mathrm{m}^{2}\right)$

\begin{tabular}{|c|}
\hline Experimental \\
\hline $23.20 \pm 0.91$ \\
\hline $58.56 \pm 4.88$ \\
\hline $161.05 \pm 5.10$ \\
\hline $22.57 \pm 1.54$ \\
\hline
\end{tabular}

\begin{tabular}{|c|}
\hline Control \\
\hline $23 \pm 0.81$ \\
\hline $61.18 \pm 2.48$ \\
\hline $162.60 \pm 1.89$ \\
\hline $23.13 \pm 0.58$ \\
\hline
\end{tabular}

\section{Mouth rinsing}

$23.30 \pm 0.67$

$63.65 \pm 2.38$

$164.30 \pm 2.49$

$23.51 \pm 0.28$

0.96, $M C V: P=0.90)$. Lipid profiles $(T G, T C, L D L)$ were significantly changed after one session of beetroot juice intake (TG: $P=0.005, T C: P=0.015, L D L: P=0.0001$ ). $H D L$ and TAC exhibited changes after acute beetroot juice consumption (HDL: $\mathrm{P}=0.87, \mathrm{TAC}: \mathrm{P}=$ 0.82) (Table 2).

TABLE 2: Hematological parameters, lipid profiles and TAC values before and after beetroot juice consumption (mean $\pm \mathrm{SD}$ ).

\begin{tabular}{|c|c|c|c|c|c|}
\hline Variable & Groups & Pretest & Posttest & $\mathbf{P}$ & $\mathbf{T}$ \\
\hline \multirow[t]{3}{*}{$\mathrm{Hb}(\mathrm{g} / \mathrm{dl})$} & Experimental & $12.77 \pm 0.44$ & $12.82 \pm 0.46$ & 0.39 & -0.88 \\
\hline & Control & $12.87 \pm 0.41$ & $12.81 \pm 0.39$ & 0.051 & 2.25 \\
\hline & Mouth rinsing & $12.40 \pm 0.86$ & $12.38 \pm 0.87$ & 0.08 & 1.96 \\
\hline \multirow[t]{3}{*}{ НСТ (\%) } & Experimental & $39.06 \pm 1.70$ & $39.33 \pm 2.18$ & 0.17 & -1.47 \\
\hline & Control & $41.37 \pm 1.18$ & $41.36 \pm 1.17$ & 0.34 & 1 \\
\hline & Mouth rinsing & $38.56 \pm 2.70$ & $38.55 \pm 2.71$ & 0.16 & 1.50 \\
\hline \multirow[t]{3}{*}{$\operatorname{RBC}\left({ }^{*} 10^{6} / \mu \mathrm{l}\right)$} & Experimental & $4.31 \pm 0.16$ & $4.33 \pm 0.25$ & 0.52 & -0.65 \\
\hline & Control & $4.46 \pm 0.32$ & $4.44 \pm 0.30$ & 0.16 & 1.50 \\
\hline & Mouth rinsing & $4.59 \pm 0.20$ & $4.58 \pm 0.19$ & 0.09 & 1.8 \\
\hline \multirow[t]{3}{*}{ Iron ( $\mu \mathrm{g} / \mathrm{dl})$} & Experimental & $86.20 \pm 18.76$ & $86.30 \pm 22$ & 0.96 & -0.04 \\
\hline & Control & $87.70 \pm 15.46$ & $85.10 \pm 13.73$ & 0.56 & 0.60 \\
\hline & Mouth rinsing & $83.80 \pm 15.49$ & $82.50 \pm 19.81$ & 0.74 & 0.33 \\
\hline \multirow[t]{3}{*}{ MCV (fL) } & Experimental & $91.92 \pm 1.43$ & $91.91 \pm 1.36$ & 0.90 & 0.12 \\
\hline & Control & $90.57 \pm 3.28$ & $90.70 \pm 3.59$ & 0.70 & -0.38 \\
\hline & Mouth rinsing & $89.65 \pm 2.96$ & $89.60 \pm 3.20$ & 0.72 & 0.37 \\
\hline \multirow[t]{3}{*}{ TG (mg /dl) } & Experimental & $97.60 \pm 45.62$ & $97 \pm 45.56$ & $0.005^{*}$ & 3.67 \\
\hline & Control & $125.20 \pm 43.44$ & $124.90 \pm 43.32$ & 0.08 & 1.96 \\
\hline & Mouth rinsing & $148.20 \pm 62.71$ & $147.90 \pm 62.90$ & 0.19 & 1.40 \\
\hline \multirow[t]{3}{*}{ TC (mg /dl) } & Experimental & $119.50 \pm 23.28$ & $119 \pm 23.11$ & $0.015^{*}$ & 3 \\
\hline & Control & $135.50 \pm 34.82$ & $135.20 \pm 34.67$ & 0.08 & 1.96 \\
\hline & Mouth rinsing & $175.40 \pm 48.23$ & $175.50 \pm 47.77$ & 0.75 & -0.31 \\
\hline \multirow[t]{3}{*}{ HDL(mg/dl) } & Experimental & $46.70 \pm 3.26$ & $46.60 \pm 2.50$ & 0.87 & 0.16 \\
\hline & Control & $48.30 \pm 4.21$ & $48.10 \pm 4.01$ & 0.44 & 0.80 \\
\hline & Mouth rinsing & $57 \pm 5.96$ & $56.90 \pm 6.10$ & 0.72 & 0.36 \\
\hline
\end{tabular}




\begin{tabular}{lccccc} 
Variable & Groups & Pretest & Posttest & P & T \\
LDL (mg/dl) & Experimental & $66.90 \pm 8.04$ & $65.10 \pm 8.29$ & $0.0001^{*}$ & 13.50 \\
& Control & $65.70 \pm 13.19$ & $65.50 \pm 13.16$ & 0.44 & 0.80 \\
& Mouth rinsing & $88.80 \pm 21.47$ & $88.60 \pm 21.35$ & 0.16 & 1.50 \\
\hline TAC (mmol /lit) & Experimental & $0.227 \pm 0.021$ & $0.228 \pm 0.027$ & 0.82 & -0.22 \\
& Control & $0.241 \pm 0.043$ & $0.241 \pm 0.043$ & 0.13 & 1.64 \\
& Mouth rinsing & $0.206 \pm 0.010$ & $0.206 \pm 0.010$ & 0.29 & -1.11
\end{tabular}

Abbreviation: $\mathrm{Hb}$, hemoglobin; Hct, hematocrit; $\mathrm{RBC}$, red blood cell; $\mathrm{MCV}$, mean corpuscular volume; TG, triglyceride; TC, total cholesterol; HDL, high density lipoprotein; LDL, low density lipoprotein; TAC, total antioxidant capacity

TABLE 3: Comparison of hematological parameters, lipid profile, and TAC between experimental, control, and mouth rinsing) groups $(n=10)$.

Variable
$\mathrm{Hb}(\mathrm{g} / \mathrm{dl})$
Hct $(\%)$
$\operatorname{RBC}\left(* 10^{6} / \mu \mathrm{l}\right)$
$\operatorname{Iron}(\mu \mathrm{g} / \mathrm{dl})$
MCV $(\mathrm{fL})$
$\operatorname{TG}(\mathrm{mg} / \mathrm{dl})$
$\operatorname{TC}(\mathrm{mg} / \mathrm{dl})$
$\operatorname{HDL}(\mathrm{mg} / \mathrm{dl})$
$\operatorname{LDL}(\mathrm{mg} / \mathrm{dl})$
$\operatorname{TAC}(\mathrm{mmol} / \mathrm{l})$

\begin{tabular}{|c|}
\hline Sum of squares \\
\hline 0.06 \\
\hline 0.52 \\
\hline 0.01 \\
\hline 36.46 \\
\hline 0.17 \\
\hline 0.60 \\
\hline 1.86 \\
\hline 8.86 \\
\hline 17.06 \\
\hline 0.0001
\end{tabular}

\begin{tabular}{|c|}
\hline Mean square \\
\hline 0.03 \\
\hline 0.26 \\
\hline 0.005 \\
\hline 18.23 \\
\hline 0.08 \\
\hline 0.30 \\
\hline 0.93 \\
\hline 4.43 \\
\hline 8.53 \\
\hline 0.0001
\end{tabular}

\begin{tabular}{|c|}
\hline P value \\
\hline 0.11 \\
\hline 0.11 \\
\hline 0.33 \\
\hline 0.87 \\
\hline 0.82 \\
\hline 0.40 \\
\hline 0.17 \\
\hline 0.16 \\
\hline 0.0001 \\
\hline 0.94 \\
\hline
\end{tabular}

\begin{tabular}{|c|}
\hline $\mathbf{F}$ \\
\hline 2.33 \\
\hline 2.32 \\
\hline 1.15 \\
0.13 \\
0.19 \\
0.94 \\
1.86 \\
1.91 \\
18 \\
\hline 0.06
\end{tabular}

The above results indicated that there were no significant differences in hematological parameters (hemoglobin, hematocrit, RBC, iron, MCV), lipid profiles (triglyceride, total cholesterol, $\mathrm{HDL}$ ) and total antioxidant capacity between groups (experimental, control and mouth rinsing) (Hb: $P=0.11$, Hct: $P=0.11, R B C: P=0.33$, iron: $P=0.87, M C V: P=$ 0.82, TG: $P=0.40, T C: P=0.17, \mathrm{HDL}: P=0.16$, TAC: $P=0.94$ ), whereas $L D L$ exhibited a significant difference after one session of drinking beetroot juice $(P=0.0001)$.

\section{Discussion}

This randomized study investigated the effects of acute beetroot juice intake for one session on hematological parameters, lipid profiles and TAC in trained female soccer players. To our knowledge, this is the first study that evaluated the effectiveness of acute beetroot juice consumption on blood indices, lipid profiles and TAC in female soccer players. During this research, we found that there was no significant difference in blood parameters (hemoglobin, hematocrit, RBC, iron, and MCV), lipid profiles (triglyceride, 
total cholesterol, and HDL) and TAC between experimental, control and mouth rinsing groups. However, there was a significant difference involving LDL between groups. In similar studies that have been conducted involving human subjects (non-athletes), data recorded significant improvements in blood indices after long-term consumption of beetroot juice [6, 19-21]. In this regard, many further studies should be conducted involving athletes. Moreover, there is little information regarding anti-lipid effects of beetroot juice in humans, especially female soccer players. Holy et al (2017) investigated the effects of one session of beetroot juice intake on lipid profiles in apparently healthy individuals. Their research showed notable changes in triglycerides, cholesterol, and LDL, without any significant change in HDL, which is consistent with the results of the present study [16]. In other studies, researchers reported significant changes in lipid profiles after chronic intake of beetroot juice $[22,23]$. This information reminds us that the more a person drinks beetroot juice, the more a person may benefit from its antilipid properties. More research must be conducted involving athletes, especially female soccer players. In addition, soccer training can lead to the production of large amounts of reactive oxygen species, which can reduce time to fatigue and affect athletic performance. The body's defense systems also tackle these compounds, but sometimes face defeat. Limited studies have been conducted regarding the antioxidant properties of beetroot juice, but these have shown improvement in antioxidant capacity in animal and human cases (non-athletes) after long duration intake of beetroot juice [24-27]. These results were not in accordance with those of the present study. As we have confined our focus regarding the antioxidant effects of drinking beetroot juice in female soccer players, studies in this area should be carried out by future researchers. Moreover, daily consumption of beetroot juice with different doses and its effects on health and performance in a large number of soccer players of both sexes and in different training intensities must be evaluated in further studies. Finally, if benefits are observed, female soccer players must include this juice in their diet as a drink that promotes health and performance.

\section{Ethical considerations}

Ethical issues (including plagiarism, informed consent, misconduct, data fabrication and/or falsification, double publication and/or submission, redundancy, etc.) have been completely observed by the authors. 


\section{Acknowledgements}

Thanks to all participants for their contribution to this research. This paper was extracted from a Master's degree thesis.

\section{Conflicts of Interest}

The authors declare that they have no conflicts of interest.

\section{Author's' Contribution}

Study concept and design: M. azizi and M. lotfi. Analysis and interpretation of data: W. Tahmasebi and M. Lotfi. Drafting of the manuscript: M. azizi and M. lotfi and W. Tahmasebi and P. Bashiri. Critical revision of the manuscript for important intellectual content: $\mathrm{M}$. azizi and M. lotfi.

\section{References}

[1] Kumari J, Awan RH, Nayab S, Awan KH. Anemia. Prof Med J. 2019;26(1):59-63.

[2] Brownlie IV T, Utermohlen V, Hinton PS, Haas JD. Tissue iron deficiency without anemia impairs adaptation in endurance capacity after aerobic training in previously untrained women. Am J Clin Nutr. 2004;79(3):437-43.

[3] Merkel D, Huerta M, Grotto I, Blum D, Rachmilewitz E, Fibach E, et al. Incidence of anemia and iron deficiency in strenuously trained adolescents: results of a longitudinal follow-up study. J Adol H. 2009;45(3):286-291.

[4] Martinović J, Kotur-Stevuljević J, Dopsaj V, Dopsaj M, Stefanović A, Kasum G. Paraoxonase activity in athletes with depleted iron stores and iron-deficient erythropoiesis. Clin Bioch. 2010;43(15):1225-29.

[5] Francés GML, Rigual MR, Sien MTM. Nutrición en el desarrollo puberal. Necesidades energéticas y valoración clínica de su cumplimiento en el paciente diabético. Act Diet. 2009;13(3):108-114.

[6] Priya NG, Malarvizhi M, Jothi A. Beet root juice on haemoglobin among adolescent girls. J Nut H Sci. 2013;2(1):9-13.

[7] Al-Dosari M, Alqasoumi S, Ahmed M, Al-Yahya M, Ansari MN, Rafatullah S. Effect of Beta vulgaris L. on cholesterol rich diet-induced hypercholesterolemia in rats. Farm. 2011;59(4):669-78. 
[8] Gilchrist M, Winyard PG, Fulford J, Anning C, Shore AC, Benjamin N. Dietary nitrate supplementation improves reaction time in type 2 diabetes: development and application of a novel nitrate-depleted beetroot juice placebo. Nit Oxi. 2014;40(7):6774.

[9] Jajja A, Sutyarjoko A, Lara J, Rennie K, Brandt K, Qadir O, et al. Beetroot supplementation lowers daily systolic blood pressure in older, overweight subjects. Nut Res. 2014;34(10):868-75.

[10] Michael M. Gaschler BRS. Lipid peroxidation in cell death. Bio Res Com. 2016;482(2):419-25.

[11] Dokumaci B, Akdogan E, Cerrah AO, Cakir-Atabek H. Relationship between oxidative stress indices and aerobic/anaerobic capacity in u17 soccer players. Fres Envir Bull. 2018;27(4):2449-55.

[12] Goldfarb AH, McKenzie MJ, Bloomer RJ. Gender comparisons of exercise-induced oxidative stress: influence of antioxidant supplementation. Appl Phys Nut Met. 2007;32(6):1124-31.

[13] Clifford T, Howatson G, West D, Stevenson E. The potential benefits of red beetroot supplementation in health and disease. Nut. 2015;7(4):2801-22

[14] Vasconcellos J, Conte-Junior C, Silva D, Pierucci AP, Paschoalin V, Alvares TS. Comparison of total antioxidant potential, and total phenolic, nitrate, sugar, and organic acid contents in beetroot juice, chips, powder, and cooked beetroot. Fd Sci Biotech. 2016;25(1):79-84

[15] Bond V, Curry BH, Adams RG, Asadi MS, Millis RM, Haddad GE. Effects of dietary nitrates on systemic and cerebrovascular hemodynamics. Cardio Res Prac. 2013;4(3):1-9.

[16] Brown Holy NNlaBON. Post-prandial effect of beetroot (beta vulgaris) juice on glucose and lipids levels of apparently healthy subjects. Eur J Pharm Med Res. 2017;4(5):60-62.

[17] Wightman EL, Haskell-Ramsay CF, Thompson KG, Blackwell JR, Winyard PG, Forster J, et al. Dietary nitrate modulates cerebral blood flow parameters and cognitive performance in humans: a double-blind, placebo-controlled, crossover investigation. Physio Behv. 2015;14(9):149-58.

[18] Hoon MW, Jones AM, Johnson NA, Blackwell JR, Broad EM, Lundy B, et al. The effect of variable doses of inorganic nitrate-rich beetroot juice on simulated 2000-m rowing performance in trained athletes. Int J Nurs Educ Res. 2017;5(2):140-142. 
[19] Patel R, Luke F. A Study to Assess the Effectiveness of Beetroot Juice with Jaggery on Anemia among Adolescent Girls in the Selected Urban Area at Rajkot. Int J Nurs Educ Res. 2017;5(2):140-42.

[20] Kale R, Sawate A, Kshirsagar R, Patil B, Mane R. Studies on evaluation of physical and chemical composition of beetroot (Beta vulgaris L.). Int J Clin Sci. 2018;6(2):2977-79.

[21] Al-aboud NM. Effect of red beetroot (Beta vulgaris L.) intake on the level of some hematological tests in a group of female volunteers. J Fd Agri Sci. 2018;8(2):10-17.

[22] Singh A, Verma SK, Singh VK, Nanjappa C, Roopa N, Raju PS, et al. Beetroot Juice Supplementation Increases High Density Lipoprotein-Cholesterol and Reduces Oxidative Stress in Physically Active Individuals. J Pharm Nut Sci. 2015;5(3):179-85.

[23] Rabeh MN, Ibrahim EM. Antihypercholesterolemic Effects of Beet (Beta vulgaris L.) Root Waste Extract on Hypercholesterolemic Rats and its Antioxidant Potential Properties. Pak J Nut. 2014;13(9):500.

[24] Kujawska M, Ignatowicz E, Murias M, Ewertowska M, Mikołajczyk K, JodynisLiebert J. Protective effect of red beetroot against carbon tetrachlorideand $\mathrm{N}$-nitrosodiethylamine-induced oxidative stress in rats. J Agri Fd Chem. 2009;57(6):2570-75.

[25] Lu X, Wang Y, Zhang Z. Radioprotective activity of betalains from red beets in mice exposed to gamma irradiation. Eur J Pharm. 2009;61(5):223-27.

[26] El Gamal AA, AlSaid MS, Raish M, Al-Sohaibani M, Al-Massarani SM, Ahmad A, et al. Beetroot (Beta vulgaris L.) extract ameliorates gentamicin-induced nephrotoxicity associated oxidative stress, inflammation, and apoptosis in rodent model. Med Inflam. 2014;2(1):4-11.

[27] Roth T. Benefits of beetroot supplementation on maximal exercise, blood pressure, and the redox state of blood. Prof Med J. 2015;11(5):23-32. 